\title{
Incidence and clinical outcomes of atypical pituitary adenomas
}

Ahmad A. Moussa ${ }^{1,2^{*}}$, Mohamed E. Mahmoud ${ }^{1}$ and Hosam A. Yousef ${ }^{3}$

\begin{abstract}
Background: Atypical pituitary adenoma has a high rate of recurrence and most of them need further treatment after surgery. This is why early detection is very important.

Methods: In this study we examined the incidence and outcome of large atypical pituitary adenoma in our patient cohort. The study was a retrospective review of fifty consecutive patients at Assiut university hospital. They all had a large adenoma with supracellar and parasellar extension. They were considered unsuitable for transphenoidal approach. They all had craniotomy. This study was carried out during a thirty eight month period. Pathology reports were reviewed. All patients had MIB-1 immunohistochemical data. Patients with lesions showing excessive MIB-1immunoreactivity and mitotic features had p53 immunohistochemical data.
\end{abstract}

Results: Ten (20\%) of our patients had lesions that met all the criteria for atypical adenoma.

Conclusion: Atypical pituitary adenoma tend to be aggressive and invasive macroadenomas. Following surgery, further treatment such as radiotherapy should be considered.

Keywords: Atypical pituitary adenoma, Craniotomy

\section{Background}

The World Health Organisation (WHO) categorises pituitary tumours as typical adenomas, atypical adenomas and pituitary carcinomas, with typical adenomas constituting the major class. Classified atypical adenomas do not all have clinically atypical features or exhibit aggressive behaviours.

The diagnostic criteria for an atypical pituitary adenoma, according to the latest WHO classification, includes excess p53 immunoreactivity, MIB-1 proliferative index greater than $3 \%$, and increased mitotic activity [1].

Atypical adenomas, defined from a clinical perspective, have earlier and more frequent recurrences than typical adenomas. Hence, there is a need to develop new biomarkers to facilitate the earlier detection of clinically atypical adenomas and there have been many attempts to develop such markers [2].

However, the WHO Classification does not provide an accurate correlation between histological findings and clinical behaviours [3].

\footnotetext{
* Correspondence: ahmad_a_moussa@yahoo.com

${ }^{1}$ Department of Neurosurgery, Assiut University Hospital, Assiut, Egypt

${ }^{2}$ Department of Neurosurgery, University Hospitals Birmingham, Birmingham, UK

Full list of author information is available at the end of the article
}

Early detection of atypical adenoma is important for improving the management of patients and effectiveness of treatment.

\section{Results}

On imaging, all 50 patients had a macroadenoma with suprasellar extension, and $11(22 \%)$ out of the $50 \mathrm{pa}$ tients had evidence of basal surrounding invasion.

On clinical grounds, six (12\%) of our patients had hormonally active tumours but most of our patients had non-functioning lesions.

Immunohistochemical analysis demonstrated the following: growth hormone (GH)-secreting adenoma in two (4\%) patients, null-cell adenoma in four (8\%) patients, adrenocorticotrophic hormone (ACTH)-staining tumour with Cushing's disease in two (4\%) patients and silent follicle stimulating hormone (FSH)-staining tumour in eight (16\%) patients.

Nearly total resection was demonstrated radiologically in most of the 50 patients. The mean follow-up period for our patients was 26.6 (ranging 18-38) months.

Ten $(20 \%)$ of the 50 patients had lesions that met all the criteria for atypical pituitary adenoma. Five patients were female and five were male. Their age ranged from 


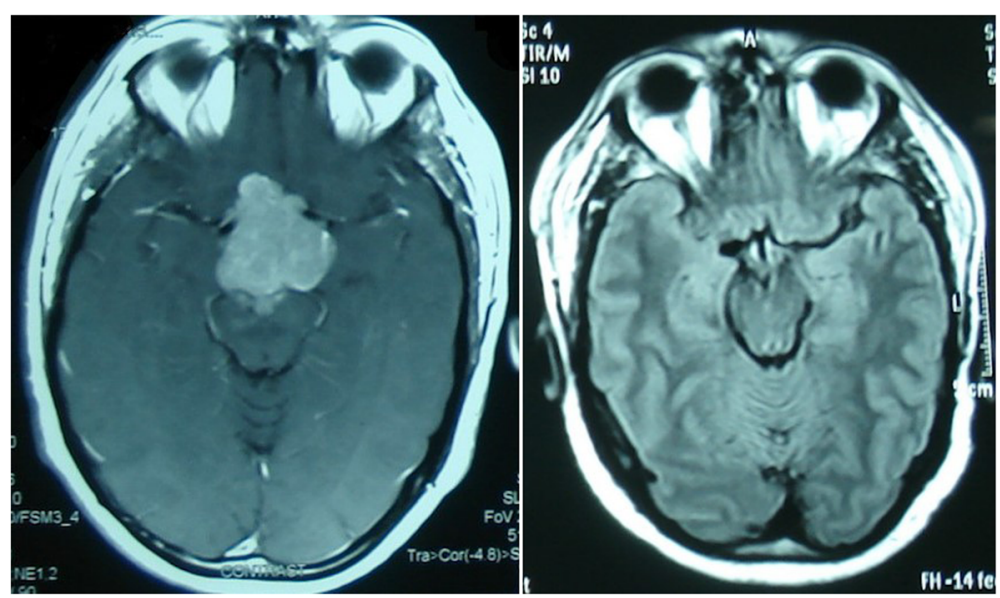

Fig. 1 Example 1, pre- and postoperative scans

29 to 80 years, with a mean age of 49 . The other 40 patients each had some, but not all, of the features of atypical pituitary adenoma.

During the follow-up period, three $(30 \%)$ of the ten patients had no recurrence of the tumour, four (40\%) out of the ten patients had recurrence of the tumour but did not require surgery and three $(30 \%)$ out of the ten patients had recurrence which required further surgery.

None of the other 40 patients had recurrence of the tumour during the follow-up period.

\section{Discussion}

Diagnostic criteria, according to the 2004 WHO Classification, of atypical adenoma are having elevated MIB-1 proliferative index greater than 3\%, high p53 immune activity, increase mitotic activity and pleomorphism. The accuracy of these diagnostic factors taken collectively has not been assessed, particularly in relation to the degree of surrounding invasion and tumour recurrence rate.

Expression of p53 has also been shown to correlate with the aggressiveness of pituitary adenomas and numerous other neuroplastic lesions in selected studies. In 2005, Saeger et al. reported an incidence of $2.7 \%$ of atypical pituitary tumours among 451 cases from the German Pituitary Tumour Registry who underwent transphenoidal surgery [4]. Salehi et al. [5] noted several variations in the definition of invasion among previous studies reviewed, ranging from assessment based on imaging studies, to histopathological evidence of dural invasion to intra-operative observations.

The aim of the current study was to identify the incidence of tumours satisfying the 2004 WHO criteria for atypical pituitary adenomas. The incidence of atypical adenoma in 50 patients undergoing craniotomy for pituitary adenoma at Assiut University Hospital was $20 \%$.

Our results are similar to those of Zada et al. [6] who, in 2011, published a series of 121 consecutive patients with pituitary adenomas who underwent transphenoidal surgery. The incidence of atypical adenoma among their series was $15 \%$.

All our patients had macroadenoma with suprasellar extension, and most of them had evidence of tumour invasion into surrounding structures. Clinically, most of

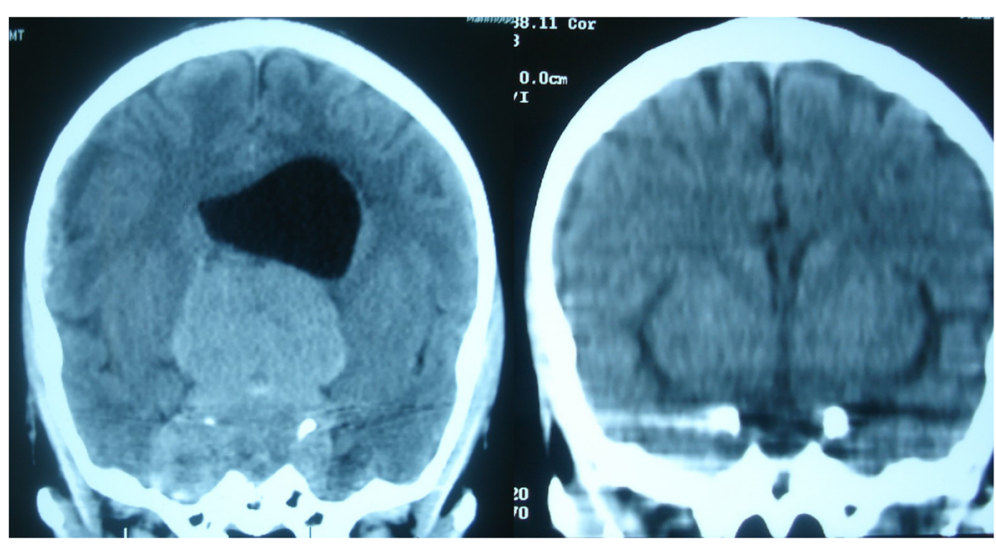

Fig. 2 Example 2, pre- and postoperative scans 
our patients had restriction of their visual fields or partial diminution of visual acuity or both.

\section{Conclusion}

Atypical pituitary adenomas tend to be aggressive and invasive adenoma.

Its incidence in our group was 20\% (ten out of 50 patients).

They have a high rate of recurrence. In our series, it was $70 \%$ (four and three out of ten patients).

They require close follow-up and early consideration of further treatment such as radiotherapy.

\section{Methods}

This is a retrospective analysis of 50 consecutive patients who had craniotomy, for pituitary adenoma, over a period of 38 months. The pathology was consistent with a pituitary adenoma in all 50 cases performed for sellar lesions during this period. The pathology reports of all our patients were reviewed to identify lesions that met the criteria for atypical pituitary adenoma.

The clinical features and neuro-images of our patients were reviewed to identify characteristics associated with atypical adenoma (Figs. 1 and 2). Clinical outcomes were evaluated over a minimum follow-up period of 36 months.

\section{Research design}

This is a retrospective study analysing historical data from patients' records and scans that were carried out at Assiut University Hospital.

\section{Immunohistochemical analysis}

Histological examination was carried out on formalinfixed paraffin-embedded sections of specimens taken from lesions of all 50 patients.

MIB-1 (proliferative index) immunohistochemical analysis was performed on all specimens. In lesions that had excessive MIB-1 immunoactivity and mitotic features, p53 immunohistochemical analysis was performed.

\section{Availability of data and materials}

Data sharing is not applicable to this article as no datasets were generated or analysed during the current study.

\section{Authors' contributions}

AAM is the main author who contributed to the study design and writing of the publication. MEM contributed to the data collection. HAY contributed to the data collection, analysis of the patients' scans, and writing of the publication.

All authors read and approved the final manuscript.

\section{Ethics approval and consent to participate}

Research committee approval has been granted for this study by the Chairman of the Medical Ethics Committee, Prof. H. N. El Tallawy, with ethics committee approval number 17300200 .

\section{Publisher's Note}

Springer Nature remains neutral with regard to jurisdictional claims in published maps and institutional affiliations.

\section{Author details}

${ }^{1}$ Department of Neurosurgery, Assiut University Hospital, Assiut, Egypt.

${ }^{2}$ Department of Neurosurgery, University Hospitals Birmingham, Birmingham,

UK. ${ }^{3}$ Department of Radiology, Assiut University Hospital, Assiut, Egypt.

Received: 17 January 2018 Accepted: 27 April 2018

Published online: 30 July 2018

References

1. De Lellis RA, Lloyd RV, Heitz PU, Eng C, editors. Pathology and genetics: tumours of endocrine organs (World Health Organisation Classification of Tumours). Third ed. Lyon: IARC Press; 2004.

2. Di Leva A, Rotondo F, Syr LV, Cusimano MD, Kovals K. Aggressive pituitary adenoma—diagnosis and emerging treatment. Nat Rev Endocrinol. 2014;10: 423-35.

3. De Leva A, Rotunda F, Syro LV, Cusimmano MD, Kovacs K. Aggressive pituitary adenoma- diagnosius and emergiong treatment: nature review. Endocrinology. 2014;10:423.

4. Saeger W, Ludecke DK, Buchfelder M, Fahlbusch R, Quabbe HJ, Petersen S. Pathological classification of pituitary tumours: 10 years of experience with the German Pituitary Registry. Eur J Endocrinol. 2007;156:203-16.

5. Salehi F, Agjur A, Scheithauer BW, Kovacs K, Lloyd RV, Cusimano M. Kl-67 in pituitary neoplasms: a review-part1. Neurosurgery. 2009;865:429-37.

6. Zada G, Woodmansee WW, Ramkissoon S, Amadio J, Nose V, Laws ER Jr. Atypical pituitary adenomas: incidence, clinical characteristics and implications. J Neurosurg. 2011;114(No2):336-44.

\section{Submit your manuscript to a SpringerOpen ${ }^{\circ}$ journal and benefit from:}

- Convenient online submission

- Rigorous peer review

- Open access: articles freely available online

- High visibility within the field

- Retaining the copyright to your article

Submit your next manuscript at $>$ springeropen.com 